\title{
The Practice of Physical Medicine and Rehabilitation in subSaharan Africa and Antarctica: A White Paper or a Black Mark?
}

\author{
Andrew J. Haig, MD, Jonathan Im, Ayodeji Adewole, MD, \\ Virgina S. Nelson, MD, MPH, Brian Krabak, MD, MBA; The International \\ Rehabilitation Forum Commission on Physiatry in subSaharan Africa
}

Objective: The medical specialty of physical medicine and rehabilitation (PM\&R) has had a proven impact on persons with disability and on health care systems. Documents such as The White Book on Physical and Rehabilitation Medicine in Europe have been important in defining the scope of practice within various regions. However, on some continents, the practice has not been well defined.

Design: To explore the practice of PM\&R in subSaharan Africa and Antarctica.

Methods: Medline searches, membership data searches, fax survey of medical schools, Internet searches, and interviews with experts.

Results: The continents are dissimilar in terms of climate and government. However both Antarctica and subSaharan Africa have no PM\&R training programs, no professional organizations, no specialty board requirements, and no practicing physicians in the field. Because there are no known disabled children on Antarctica and adults are airlifted to world-class health care, the consequences of this deficit are minimal there. However, the 788,000,000 permanent residents of subSaharan Africa, including approximately 78 million persons with disability, are left unserved.

Conclusions: Antarctica is doing fine. Africa is in a crisis. Local medical schools, hospitals doctors, and persons with disability; along with foreign volunteers, aid groups, and policymakers can impact the crisis. However government-specifically national ministries of health-is ultimately responsible for the health and wellbeing of citizens.

\section{INTRODUCTION}

The World Health Organization (WHO) estimates that 1 in 10 persons in the world has a significant disability [1]. There is extensive literature showing the effectiveness and costeffectiveness of medical rehabilitation in returning persons with disability to independence and to productive lives [2]. Over the last half century, this literature, along with the intuitive observation of those who have been exposed to rehabilitation, has led to the rapid growth of the physician specialty that drives the medical rehabilitation process-physical medicine and rehabilitation (PM\&R), or physiatry.

In Europe, the Americas, Asia, and Australia, tens of thousands of physician specialists in the field of physiatry practice their trade of caring for people with strokes, brain injuries, spinal cord injuries, arthritis, back pain, developmental disabilities, and numerous other medical disorders in settings, ranging from private offices to large comprehensive medical rehabilitation hospitals. As this valuable "field that owns no organ system" has matured, regional organizations in America, Europe, and Asia have codified the specialty and quantified the reach of the field [3-5].

Perhaps the most influential and detailed of these is the White Book on Physical and Rehabilitation Medicine in Europe [4,6]. The result of collaboration between 3 different continent-wide specialty organizations, the White Book was published simultaneously in 2 major journals. Its 46 pages document the problem of disability, the relevance of rehabilitation to persons with disability and to society, and the principles of PM\&R. It defines the

A.J.H. Department of Physical Medicine and Rehabilitation, The University of Michigan, 325 E. Eisenhower, Ann Arbor, Ml 48108. Address correspondence to: A.J.H.; e-mail: andyhaig@umich.edu Disclosure: nothing to disclose.

J.I. Wayne State University, College of Liberal Arts and Sciences, Detroit, MI

Disclosure: nothing to disclose.

A.A. SOS International, Accra, Ghana Disclosure: nothing to disclose.

V.S.N. The University of Michigan Department of Physical Medicine and Rehabilitation, Ann Arbor, Ml

Disclosure: nothing to disclose.

B.K. The University of Washington Department of Rehabilitation Medicine, Seattle, WA Disclosure: nothing to disclose.

Disclosure Key can be found on the Table of Contents and at www.pmrjournal.org

Submitted for publication December 12 2008; accepted December 13, 2008

This article will also appear in the European Journal of Physical and Rehabilitation Medicine, Disability and Rehabilitation, Journal of Rehabilitation Medicine, and the Chinese Journal of PM\&R. 
specialty as it is practiced in Europe, outlines standards for clinical training and practice, and provides a framework for future research in the field. Appendices quantify the number of practitioners and trainees, as well as various aspects of practice. This document has evoked a number of commentaries and contrasts with the field as practiced elsewhere [7-9].

Two continents have notably been absent from this type of documentation-subSaharan Africa and Antarctica. subSaharan Africa is a continent of $788,000,000$ men, women, and children, many living in poverty, torn by war in some places, by infectious diseases in others [10]. Antarctica is populated by approximately 4000 wealthy scientists, most of whom go home for the winter, and a large number of penguins [11]. The International Rehabilitation Forum (IRF, www.rehabforum.org) is an organization supported by a consortium of major academic PM\&R departments, with a goal of uniting them to build medical rehabilitation throughout the world. Because no other organization appears to represent the specialty in these 2 regions, the IRF set out to provide documentation of the specialty as practiced in these regions.

\section{METHODS}

A commission was established to seek out the leaders of all African and Antarctican professional specialty societies in physiatry. Having found none, the IRF determined to include leading physicians practicing the specialty in Africa and Antarctica. Having found none, the IRF then sought out the most expert persons we could find: a Ghanaian general practitioner who had been awarded the Globus Fellowship from the International Society for the Study of the Lumbar Spine to study spine rehabilitation in the United States, an American physiatrist who has volunteered for many years in East Africa, another American physiatrist who has consulted on program building with universities and governments in West Africa, and an undergraduate student who was adept at Internet searches. To represent Antarctica, we included a physiatrist who had visited the continent as medical director for an ultra-endurance running race.

The team performed a Medline literature search on the terms physiatry or physical medicine and the various continents, covering the years between 1950 and October 2008. The membership list of the International Society for Physical and Rehabilitation Medicine was searched for members from African countries. A Boolean search of Internet resources including Google, Google Scholar, PubMed articles, National Library of Medicine, CINAHL, Cochrane, and Medline Plus for Physical Medicine and Rehabilitation or Physiatry and Africa (including various nations) or Antarctica was performed, and the highest ranked hits were traced to determine if they contained any evidence for the practice of physiatry on the continents.

No medical schools were found in Antarctica. All subSaharan medical schools listed on websites for the Institute for International Medical Education and the IMED online search (www.iime.org/database/index.htm) were sought. These in-

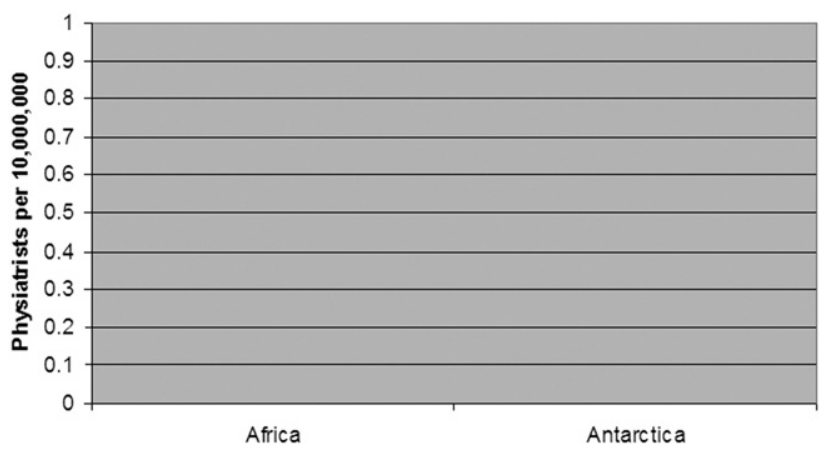

Figure 1. The number of physiatrists per 10 million people in subSaharan Africa and in Antarctica.

cluded schools in: Angola, Benin, Botswana, Burkina Faso, Burundi, Cameroon, Republic of Cape Verde, Central African Republic, Chad, Comoros, Democratic Republic of Congo, Republic of Congo, Côte d'Ivoire, Djibouti, Equatorial Guinea, Eritrea, Ethiopia, Gabon, The Republic of the Gambia, Ghana, Guinea, Guinea-Bissau, Kenya, Lesotho, Liberia, Madagascar, Malawi, Mali, Mauritania, Mauritius, Mozambique, Namibia, Niger, Nigeria, Rwanda, Sao Tome and Principe, Senegal, Seychelles, Sierra Leone, Somalia, South Africa, Swaziland, Tanzania, United Republic of Togo, Uganda, Zambia, and Zimbabwe.

Websites of these schools, if available, were searched for any evidence of $P M \& R$ specialists. A survey was sent via fax or email to those schools that posted fax or e-mail addresses.

The commission contacted the West African College of Physicians and the South African College of Physicians asking for information on any $P M \& R$ specialists in Africa. Throughout the process, the Commission asked visitors to Africa, African expatriates, African medical personnel, and international leaders in the specialty about the practice of $\mathrm{PM} \& \mathrm{R}$ in Africa.

\section{RESULTS}

The data are best summarized by Figure 1, which illustrates the number of physiatrists per 10 million persons living in Antarctica and subSaharan Africa. Detailed analysis is performed for each continent separately, as noted in the following sections.

\section{Antarctica}

A Google search of the term Antarctica physiatry found that Brian Krabak, M.D., M.B.A., of the University of Washington, had acted as competition physician for an ultra-endurance running race in Antarctica [12]. Dr. Krabak was invited to join the commission. At the time of this article, he knew of no other physiatric presence on the continent.

\section{subSaharan Africa}

The search found no physiatry specialty organizations or specialty journals in Africa. There are no known training 


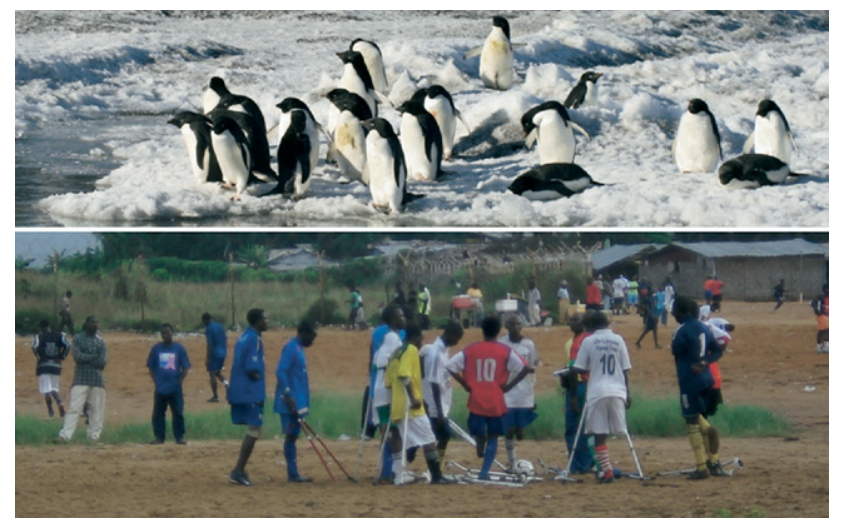

Figure 2. Above: Pygoscelis adeliae or Adelie penguin in Antarctica. Below: Homo sapiens, or humans in Africa. Both groups have a statistically similar chance of interacting with a physiatrist. Note that the penguins all have legs. (Penguin photo courtesy of Katie M. Dugger, Ph.D., Oregon State University.)

programs in Africa, and requirements for the field are not specified by any African regulatory body. No medical school website was found to have any mention of the specialty. There are no subSaharan Africa members of the International Society for Physical and Rehabilitation Medicine. Only 2 surveys were returned. One respondent suggested that there was a group of physicians somewhere in South Africa who may or may not have had formal training in the field. Contact with the South African Medical Association revealed that there were indeed 6 physicians in the country who specialized in PM\&R [13]. After extensive discussion with colleagues and numerous trips to the region, the West and East African consulting physicians were quite confident that there were no physiatrists in those regions.

The Medline search between 1950 and October 2008 found 16,132 articles on physiatry or physical medicine. For Africa below the Sahara there were 135,373 citations. Combining these, only 60 joint citations were found. A detailed analysis of these 60 showed that almost all related to allied health professionals or were irrelevant. None could be traced to a practicing African physiatrist. Aside from recent publications by the IRF, only 2 articles addressing the specialty in Africa were found. Both were written half a century ago by the same author (Table 1) [14,15].

\section{DISCUSSION}

The research results suggest that the odds of an African with a disability meeting a physician who specializes in care for him or her are essentially zero. The tragedy and absurdity of this finding is not communicated well through simple statistics. Therefore the absurd comparison with Antarctica is made clear in this article and illustrated graphically in Figure 2. Although the comparison may seem absurd, the research in preparing this work has been quite serious. The implications are both deadly to Africans and devastating to African economies.

The investigation has strengths and weaknesses. The thousands of articles relating to physiatry on other continents were not searched in detail for relevance or for authorship by native physiatrists. However, they are clearly evident of an active and vibrant field everywhere else in the world. Web searches used in this article typically turned up thousands of hits, most of which are completely irrelevant. Because of the volume, we were not able to exhaustively prove that no web citation on physiatry in subSaharan Africa exists. The response rate to the faxed survey was abysmally low. Whether that is because faxes were misdirected, arrived at offices that had no authority, or because authorities did not choose to respond, the survey results may be challenged. However, the search for individuals or organizations in Africa was fairly robust. The authors have met with African government and health leaders on a number of occasions; posed the question at numerous international specialty meetings, and earnestly sought information from leaders in the field. In the end, it is our honest belief that, aside from the handful of specialists in South Africa who are not members of the international society, there are no $P M \& R$ doctors residing in subSaharan Africa.

There are more than 10,280 specialists in $P M \& R$ in Europe, more than 7000 in the United States, and perhaps 10,000 in China. Self-evident in these numbers, but supported by a strong scientific literature, we know that multidisciplinary, physician-led rehabilitation is both effective and cost-effective in returning people with disability to the community. Currently, $80 \%$ of the world's disabled population lives in low-income countries such as those of subSaharan Africa. The WHO reports rehabilitative services-even basic physical therapy-reach only $1-2 \%$ of persons with disability [16]. It is fruitful to explore potential reasons for this mismatch in Africa.

Some would say that there is no physiatry because Africa is a desperate place. Essentially, with people dying every day, the continent cannot afford to improve the quality of life of the living. It is a poor place, but not exclusively so. In South Africa last year, 32,144 people purchased new Mercedes passenger vehicles [17]. In America, there is 1 physiatrist for every 30,000 urban dwellers-some of whom we understand do not own a Mercedes Benz [3]. There are enough rich and middle-income Africans to support physiatry. However, when an African Mercedes collides with an African Volkswagen or Ford or cow, no amount of money will bring a physiatrist to consult in the intensive care unit. The fallacy in the theory of Africa as a constant crisis is not just about the rich affording the luxury of rehabilitation. African society and the African economy depend on a positive ratio of consumption versus contribution. Everywhere one looks in Africa there are people living with disability. They live, so they consume. They are untreated, so they and their families contribute less than they could to the economy. The WHO's estimate of $10 \%$ major disability means this is a very big drag 
on the African economy. Rehabilitation is a good social investment, even in poorer regions. Countries need to invest.

Global policies to date are a failure, some would say. What policy? The WHO and many others have promoted a strategy of community-based rehabilitation (CBR) [18], in which people with disabilities and their families are taught to care for themselves. At face value, this sounds quite empowering and democratic. The process is supported strongly by many disabled persons' organizations. It may have some value in social reintegration of persons with disability. But it has clearly failed in Africa. Why? Because the initial phase of rehabilitation is intensely medical; the nursing acuity of modern rehabilitation hospitals is often compared with that of an intensive care unit. People in Africa who survive their initial injury languish until they die or face complex and irreversible complications ranging from contractures to pressure sores to spasticity to hopelessness. They go home to families who are not trained about their care and their prognosis. In the rest of the world, they go to medical rehabilitation wards run by physiatrists.

Relegating the medical part of rehabilitation to the community is akin to developing a community-based neurosurgery program. Worse. Because in Africa, the people with disability are the least educated, most impoverished, and most ostracized members of the community. CBR is a politically expedient way to allocate the least amount of funds possible to the problem. After all, uneducated villagers do try to take control over their lives. They are cheaper than doctors and they don't have the depth of medical knowledge to know what they're missing. With no experts who understand the medical aspects of rehabilitation to advise or to advocate, and with WHO blessings, governments often give complete responsibility for rehabilitation to ministries of social welfare, education, employment, or agriculture. CBR is insufficient. The WHO and other policymakers need to recognize that, in every country with reasonable rehabilitation services, the medical programs are led by physicians who dedicate their careers to this cause.

The local health care systems have some responsibility. With no physiatrist role models on the entire continent, medical school deans, department chairs, practicing physicians, and hospital administrators have no idea of what is missing. They look to orthopedic surgeons (typically very busy in the operating room and with little formal training in rehabilitation) and others to perform the services. They often view physical medicine as equivalent to physical therapy, perhaps with a nod to orthotics and prosthetics. Yet the literature on rehabilitation is clear-disability is multifactorial. A multidisciplinary team led by a physician expert always outperforms individual therapists. In fact, patient outcomes directly relate to the quality of team interaction [19]. Programs on all other continents (except Antarctica) succeed because of physiatrist coordination of teams including occupational and physical therapists, speech-language pathologists, rehabilitation nurses, rehabilitation psychologists, rehabilitation social workers, vocational rehabilitation counselors, rehabilitation engi- neers, and others. The medical expertise, leadership, and specific skills of physiatrists as documents such as the European White Book portray them are simply not understood. Local health care systems must build rehabilitation programs that look like the programs elsewhere in the world.

Deans of medical schools and the leadership of regional Colleges of Physicians might get the process started. The need for expert physicians is compelling. But aside from the absence of specialty training programs in physiatry, other serious questions reflect the unmet educational need across the medical education system. Does an African medical student realize that the baby with cerebral palsy might be smarter than he or she is? Does the African general practitioner know how to manage contracture, autonomic hyperreflexia, neurogenic bladder, and decubitus ulcers with physical means? Which medical school professor can tell the government of the functional impairment and societal cost of AIDS survival? Which of their hospital quality initiatives looks beyond the date of discharge to employment, social integration, and even sex? Leadership in these areas will not occur until these entities name chairs in physiatry, develop programs for trainees, and hire physiatrist medical directors.

African communities frequently rely on help from outside of Africa. Foreign governments typically provide exactly the aid that the African politicians request, rather than the aid that they need. So, for instance, the United States Agency for International Development spends billions of dollars to support Africa, but, aside from the small Leahy War Victims Fund, has almost no investment in rehabilitation. Major nongovernmental organizations are often more focused on acute disasters than the large chronic disaster of living with a disability. Doctors Without Borders, the Red Cross/Red Crescent, and others have no physiatric representation among their leadership. As a result, they are mostly not prepared for the medical acuity of disability management after crises. Their missions and their operational policies mean that they have less invested in the long-term goal of saving function once lives have been saved. Still, numerous small and large private aid groups know the value of rehabilitation, and strive to build sustainable rehabilitation programs in Africa. Free wheelchairs make great photo opportunities, but this kind of equipment supply without rehabilitation will never be sufficient and is not a locally sustainable intervention. Caring and thoughtful nongovernmental organizations should look at policies that grow locally trained expert physicians and allied health professionals who will make a living doing rehabilitation and teach others to do the same.

In our investigation we ran across dozens of physiatrists who volunteer their time-and then go home. They know that rehabilitation is longitudinal, multidisciplinary, and exceedingly culturally dependent. They would readily admit that they are no substitute for locally trained permanently employed specialists. They often petition their home country professional organizations for help, without much luck. Understandably, national and regional organizations exist to serve their members. But small investments in international 
Table 1. Medline search for articles with English titles from 1950 to 2008 that matched the terms "physical medicine" or "physiatry" and various continents

\begin{tabular}{lr}
\hline Americas & 2858 \\
Europe & 2492 \\
Asia & 290 \\
Africa & 60 \\
Africa (pertinent) & 2 \\
Antarctica & 0
\end{tabular}

development can rally the membership around a cause greater than their day-to-day practice. Students are drawn to a field where there is a great need and a great compassion. It may be easier to define the scope of practice in the home country by showing how the specialists build programs elsewhere. We would argue that non-African professional organizations in physiatry have self-serving reasons to reach out to developing countries.

In the final analysis, the responsibility lies with the Africans. Governments are responsible for the well-being of their people. As much as they care and as much as they may advocate, neither the people with disability, nor the specialty outside of Africa, nor the agencies that provide external funding are responsible. Although organizations such as the universities who have come together under the International Rehabilitation Forum can bring together the expertise, the responsibility rests squarely on the shoulders of each country's governing bodies. Ministries of health are charged with execution of health policy. Under the ministries, colleges of physicians are responsible for deciding on specialty training programs. Under the ministries, medical schools are responsible for training the physicians who will care for their country. These organizations must bear ultimate responsibility for failure or success, and the ministries of health must lead them responsibly.

Ministries are government, and governing bodies run on political power. Where does the political power come from? One curious observation about disability in Africa is that it does not spare the rich or the powerful or the intelligent members of society who can make changes happen. It is statistically likely that every parliament, every industry consortium, and every medical school in Africa has members who secretly identify themselves or a close family member as disabled. However, the stigma against persons with disability is so strong in many African cultures that disability is often hidden from view. The situation is reminiscent of American president Roosevelt who, in the 1940s, hid his polio from a society that readily pretended that it was not there [20]. Half a century later in America, television advertisers find that healthy wheelchair users draw positive attention to their message. This hidden power is a critical force for change, but must be unleashed by pride, shame, or commitment to do what is right.

In summary, as Figure 2 demonstrates, the chances that a disabled child in Africa receives the quality of care that children all over the rest of the world receive are similar to the chances that an Antarctic penguin is fed a mackerel by a physiatrist. The difference, however, is important: African governments are elected by the child's family and friends.

\section{ACKNOWLEDGMENTS}

There are no appropriate African rehabilitation journals; therefore, this article is published simultaneously in prestigious journals that represent the best in rehabilitation as it exists on all of the continents except Africa. The International Rehabilitation Forum wishes to thank the editors of these journals for their courage to represent this unrepresented region of the world. The White Paper/Black Mark reaffirms their commitment to the core mission of academic publication: To better human health by presenting and debating the facts.

\section{REFERENCES}

1. World Health Organization. Disability and Rehabilitation Team (DAR). http://www.who.int/ncd/disability/index.htm. Accessed November 8, 2008.

2. Cardenas DD, Haselkorn JK, McElligott JM, Gnatz SM. A bibliography of cost-effectiveness practices in physical medicine and rehabilitation: AAPM\&R white paper. Arch Phys Med Rehab 2001;82:711719.

3. American Academy of Physical Medicine and Rehabilitation. Review and update of the 1995 Physical Medicine and Rehabilitation Workforce Study. www.aapmr.org/hpl/studyc.htm. Accessed January 26, 2008.

4. Section of Physical and Rehabilitation Medicine Union Europeenne des Medecins Specialistes (UEMS). European Board of Physical and Rehabilitation Medicine. Academie Europeenne de Medecine de Readaptation. European Society for Physical and Rehabilitation Medicine. White book on physical and rehabilitation medicine in Europe. Eur Medicophys 2006;42:292-332.

5. Chino N, Ishigami S, Akai M, Liu M, Okajima Y, Koike J, et al. Current status of rehabilitation medicine in Asia: a report from New Millennium Asian Symposium on Rehabilitation Medicine. J Rehab Med 2002;34:1-4

6. White book on physical and rehabilitation medicine in Europe. J Rehab Med 2007;(45 Suppl):6-47.

7. Haig AJ. Practice of physical medicine and rehabilitation on both sides of the Atlantic: differences and the factors that drive them. Eur J Phys Rehab Med 2008;44:111-115.

8. Melvin JL. Physical and rehabilitation medicine: comments related to the White Book on Physical and Rehabilitation Medicine in Europe. Eur J Phys Rehab Med 2008;44:117-119.

9. Negrini S, Ceravolo MG. The White Book on Physical and Rehabilitation Medicine in Europe: a contribution to the growth of our specialty with no boundaries. Am J Phys Med Rehab 2008;87:601-606.

10. Population Reference Bureau. subSaharan Africa population. www prb.org. Accessed October 27, 2008.

11. Index Mundi: Antarctica population. http://www.indexmundi.com/ antarctica/population.html. Accessed October 15, 2008.

12. University of Washington Orthopedics and Sports Medicine: Brian Krabek, MD, MBA. http://www.orthop.washington.edu/uw/tabID_3374/ ItemID_85/mid_10331/Default.aspx. Accessed October 15, 2008.

13. Myburgh M. Head operations/database, South African Medical Association. E-mail communication November 6, 2008.

14. Lomey AL. Physical medicine and rehabilitation: new aims in treatment. S Afr Med J Suid-Suid-Afrik Tydskr Vir Geneeskunde 1965;39: 996-998.

15. Lomey AL. Physical medicine and rehabilitation: its scopes and problems. S Afr Med J Suid-Afrik Tydskr Vir Geneeskunde 1954;28:711-714.

16. Frye B. Review of the World Health Organization's report on disability prevention and rehabilitation. Rehab Nurs 1993;18:43-44. 
17. Mercedes-Benz Corporation. Mercedes-Benz South Africa Group in South Africa bucks the trend. Press release 27 March 2008. http:// www.autoworld.co.za/NewsArticle.aspx?Article $=5697$. Accessed November 1, 2008.

18. International Labor Organization. United Nations Educational, Cultural, and Scientific Organization, and World Health Organization. CBR: a strategy for rehabilitation, equalization of opportunities, poverty reduction and social inclusion of people with disabilities. Joint
Position Paper 2004. http://www.who.int/disabilities/publications/cbr/ en/index.html. Accessed November 2, 2008.

19. Strasser DC, Falconer JA, Herrin JS, Bowen SE, Stevens AB, Uomoto J. Team functioning and patient outcomes in stroke rehabilitation. Arch Phys Med Rehab 2005;86:403-409.

20. National Park Service. Franklin Delano Roosevelt Memorial: the struggle with disability. http://www.nps.gov/fdrm/fdr/struggle.htm. Accessed November 8, 2008. 